\title{
Cultural Differences \\ and the Importance of Trust Between \\ Volcanologists and Partners \\ in Volcanic Risk Mitigation
}

\author{
Chris Newhall $\odot$
}

\begin{abstract}
A challenge in volcanic hazards communication is to bridge the cultural and language gaps between volcanologists and those who use volcanological information. We might be nominally from a single culture, e.g., Japanese, American, Italian, etc., but the cultural gaps between volcanologists and those who use volcano information can be as wide or wider than those from one country to the next. We have different goals or agendas, different approaches to solving problems, different terminologies, different definitions of success, and different reward systems. The first step toward bridging gaps is to recognize and accept the differences — valuing each other's goals and agreeing to work as a team to satisfy both. This acceptance plus involving information users in the information gathering helps to build trust. Without such trust, players are unlikely to accept each other's advice. Mainly from personal experience, I note commonly encountered cultural differences. Then, given the cultural differences, I note the critical importance of bridging those differences with trust. Finally, I give three short case histories - from Mount St. Helens, Pinatubo, and Usu - in which trust was built and differences were successfully overcome.
\end{abstract}

\section{Introduction}

At Mount St. Helens in 1980, Cowlitz County Sheriff Les Nelson once lamented: "Trying to get a straight answer from a geologist is like trying to corner a rat in a round house."

C. Newhall $(\bowtie)$

Mirisbiris Garden and Nature Center, Santo

Domingo, Philippines

e-mail: cgnewhall@gmail.com

Advs in Volcanology (2018) 515-527

https://doi.org/10.1007/11157_2016_40

(C) The Author(s) 2017

Published Online: 15 March 2017
Geologists were not trying to hide anything, but they knew that Mount St. Helens could show a variety of behavior so they couched their answers in the kind of caveats that all scientists are taught to use. "There are several possible scenarios..." "Uncertainties are high..." and similar. Sheriff Nelson, and others, wanted simpler answers: yes, no, or, at least, most likely, probably yes, probably not, or similar. 
It is easy to imagine additional words that might be said about volcanologists, to their face or behind their backs. Here are some that I can imagine:

Volcanologists are a strange lot ... Some of them hike up and down volcanoes, digging in the dirt or whacking off pieces of rock and telling us that they know how this volcano works. Others go around planting sensors in the ground, or sniffing the gases, and tell us they know how this volcano works. Sometimes they agree, often they don't. We're told there are still others who spend all their time heating and squeezing rocks in their laboratories, or writing computer programs they say simulate real life volcanoes. They publish papers in scientific journals that only they can read, and consider their work done. If we ask them "Is it dangerous?" their answers are so ambiguous that we might do just as well with a pair of dice. Do they think we care about what will happen in the next thousand years? And if we ask them "What should we do?" they answer "Ask someone else. That's not our mandate or expertise!

Just as easily, I can imagine words of volcanologists about officials and other non-scientists:

\begin{abstract}
Officials and the public are a strange lot. They think that if we are good scientists, we should know exactly when and how each volcano will erupt. If we explain how complicated volcanoes are, and how science focuses on what isn't known, they roll their eyes in disbelief. Why, some of them even want us to give them 24-hour warnings! We aren't like seers who can divine the future! If we talk about the different ways that a volcano can kill them, they say "We don't care HOW we might get killed - just if or when. For us, a bomb falling on our head is the same as being toasted front or back." If we offer probabilities of various scenarios, they don't understand. And they keep resisting us... saying they want to stay in their homes, or on their jobs, or protect their cows. How can they expect us to keep them safe if they themselves won't take precautions?
\end{abstract}

Everyone who has travelled or worked in another culture knows that there are significant differences in values and customs from one culture to the next. This paper is a short cross-cultural look at differences within single cultures, just between scientists and those who use scientific information.

\section{The Literature of Scientific Communication}

Many books have been written about scientific communication, and how to bridge between the worlds of science and everyday life. Many excellent tips are given by Hayes and Grossman (2006), Manning (2006), Dean (2009), Olson (2009), Kennedy and Overholser (2010), Bultitude (2011), Fischhoff (2011), Graveline (2013), and other references in The Earth Institute (2014). Broad concepts of credibility and trust in risk communication are discussed by Renn and Levine (1991). Ways by which scientific uncertainty can be communicated in ways that enhance scientists' credibility are discussed by Morgan and Henrion (1990), Morgan (1998), Moss (2011), Mastrandrea et al. (2010), Pidgeon and Fischhoff (2011), and Socolow (2011). Ways by which scientists can communicate well across disciplines are discussed by Harris and Lyon (2013), among others. The present paper does not pretend to review the available literature, much less be a scholarly treatise. Rather, it presents personal experiences, which can be put by others into more general lessons of how best to communicate across professions.

\section{Cultural Differences Among Players at Volcanoes?}

Here are six cultural differences between scientists and non-scientists, as noticed during volcanic crises and as seen through my eyes as a volcanologist. By the generic term "scientist" I refer to both physical and social scientists, though my personal focus is naturally in physical science, specifically in volcanology. Some of you will correctly note stereotyping and sweeping generalizations, made in the interest of brevity. But every user group is a body of individuals. Generalizations will not apply to all, but in my experience they do apply to many! 
First, we are concerned with different problems. Scientists ask "What, when, how, and especially, WHY?" Civil defence officials and land managers are concerned with "What, when, how serious, and what can we do to keep people safe?" Engineers ask "What is the problem and what can we build to fix it?" Politicians ask "How can we balance many competing interests (and be re-elected)?" News media ask "How can we translate and convey this in interesting ways?" And citizens ask, "What should my family do?" None of these are easy questions or tasks!

Second, scientists and non-scientists have different goals and reward systems. Everyone shares the common goals of public safety and well-being, doing one's job well, and advancing one's career and pay scale. In addition, differing goals include, for research scientists, to satisfy intense curiosity and to have fun in doing so. Much of the reward for scientists is the simple satisfaction of making new discoveries. However, these days, scientists must also compete with peers for professional recognition, including metrics of academic achievement. Those at universities and research-oriented volcano observatories get rewarded primarily for their research publications or contributions to such publications, how often their publications are cited by other scientists, and their success in garnering research grants. Scientists at public-service oriented organizations may be rewarded primarily for smooth operations and providing high quality advice to those who seek it.

Career public servants such as civil defence officials or land managers typically get rewarded for protecting the lives, infrastructure, property, economies, natural resources, and well-being of communities. Local officers will be rewarded for answering directly to people of the community while officers at higher levels of government may be rewarded for aiding the development of policy and/or funding prospects for the organization. Politicians seek a variety of rewards. They seek re-election, yes, and funds for re-election, but also the satisfaction of successfully balancing between competing interests. A common requirement in times of volcanic crises is to successfully guard the safety of their constituents yet, at the same time, help them continue their lives as normally as possible, and to minimize disruption of business. Engineers are typically tasked with designing and implementing structural measures to reduce risk, and are rewarded with contracts, positive evaluations, and promotions if the project is successful. Most engineers take great pride in what they build or fix, so some of their reward is also internal. The owners of news media are driven variously by commitment to inform and serve the public and by the profit motive. News reporters are driven by similar commitment to public service, but are rewarded for column inches or minutes of airtime and editorial, peer, and public recognition.

Citizens, the most diverse group of all, need to balance keeping their families safe from the volcano and safe from other threats, including loss of crops, jobs, income, schooling, friends and social support networks, and other pillars of daily life.

Third, we speak different languages. Every field has its own specialized jargon. The jargon of scientists is a shorthand that is generally understood ONLY by scientists. Volcanological terms for major hazards like pyroclastic flows, tephra fall, and lahars all need clear definition, ideally in videos; more technical terms like magma compositions, extrusion rates, earthquake types, or monitoring technologies are best reserved for audiences who will appreciate them. Similarly, social science has its own jargon.

Engineering also has a specialized vocabulary, though more widely used and understood than that of scientists. Civil defence officials have their own jargon and acronyms, mostly non-technical but equally baffling to scientists. News media and the public use the language of everyday life.

The ways we view and draw the world are also different. Historically, geoscientists used maps and cross-sections to visualize the world in three dimensions, though increasingly those can be combined into fancy 3D graphics. Traditional maps (in plan view) and cross-sections are fine 
for geoscientists and engineers, but too abstract for most others (Haynes et al. 2007). Modern 3D visualizations, including oblique aerial views, are much better. GIS technology and the ready availability of 3D visualization tools through local-host GIS, Google Earth, Bing Maps, and other services are wonderful tools to help geoscientists communicate with non-geoscientists.

The meanings we attach to adjectives and other descriptors may be very different. Geologists have a very long view of time, far longer than of interest to most who seek advice. "Soon" to a layman might mean tomorrow while "soon" to a geologist might mean 100 years from now! Fast or slow are in the same category. The terms high and low, and possible, probable, likely and unlikely are notoriously ambiguous. Social scientists and others have documented wide ranges of numeric probabilities that different people attach to the same terms (Morgan 1998; Mastrandrea et al. 2010). Doyle and Potter (2015) recently suggested a table that translates from adjectives to probabilities of geologic hazards. In my own experience, the best ways to avoid the ambiguity of adjectives is to define them quantitatively, as in Mastrandrea et al. (2010) and Doyle and Potter (2015), or avoid them entirely by using a ladder of comparable risks as discussed later in this paper.

Fourth, we have different approaches to solving problems. In the scientific method, scientists identify a problem, propose hypotheses, gather data, and test the hypotheses (including forecasts of the future). Typically, the data gathering and interpretation involves a strong emphasis on observational skills, measurement, and quantitative assessment. Indeed, scientists like to quantify everything, including hazard and risk. Non-scientists (except engineers and a few others) are often wary of numbers, either because they don't understand them or they don't trust them. In an exception, those making policy for climate adaptation reportedly prefer numbers to qualitative descriptors (Moss 2011).

Scientists also strive for very low levels of uncertainty, such as might be acceptable for publication in peer-reviewed journals. Notwith- standing pressures to publish several papers per year or meet deadlines for project funding, scientists pride themselves in taking as much time as is needed before they offer advice, often months or years. Often, scientists resist calls to provide quick advice; at the same time, they should recognize that some decisions simply must be made quickly.

In contrast, Civil Defence leaders and land managers identify the problem, consider alternative solutions, prepare a decision matrix (e.g., cost benefit, etc.), and then make the optimal decision, sometimes within just hours or days. These decision-makers typically have higher tolerance than scientists for uncertainty, though in very high-stakes decisions such as siting of a nuclear facility, they too will pay great attention to uncertainty. Politicians follow a similar approach, though with more attention to public opinion. Accordingly, the metrics and weightings may be different. Scientific facts and advice may be just a small part of a political decision. For example, on matters of hazards and risk, scientists can evaluate hazard (and sometimes risk), but it is inevitably a political matter to evaluate how much risk the public (and the politician) is willing to accept. Decisions about acceptable risk, in turn, depend on the trade-offs between the benefits of taking the risk versus the potential losses if one takes the risk and loses. Scientific probabilities play a role, but only alongside many other factors. The role of citizens is to tell politicians and other decision makers how much risk they are willing to tolerate, and/or to 'vote with their feet' by self-evacuating if they so decide.

Engineers define the problem as best as they can in the time available, then design and implement a solution. The process may include consideration of several different designs and eventually choosing one. Sometimes, engineers express frustration with scientists if the starting or input parameters for what they are supposed to design keep changing. At some point, an engineer must lock in a design, whereas scientists keep on gathering data and, in some cases, call for a different or more flexible design. Scientists 
expect Nature and people to change; engineers may also expect change, but for their design they need a snapshot in time. Scientists emphasize uncertainty; engineers typically include a factor of safety to account for uncertainty and are ready to move on. News media generally limit themselves to reporting on how others solve problems, though some opinion or editorial pieces and some committed local reporters will actively facilitate communication between scientists, engineers, decision makers and the public. Members of the media bring special expertise in interviewing, listening, and comparing various points of view or approaches to problem solving.

Fifth, we differ in how we know what we know (epistemology). Nearly all who want to learn about a topic - scientists and non-scientists alike - start with published knowledge. The primary knowledge might be in academic journals, or in more accessible forms like books, popular magazines, Wikipedia and other sources on the internet, documentary videos, public lectures, and the like. While most of what is published is correct, all of us who publish know that there is misleading information too. The "library"sensu latu - is a great place to start, but must be read with a critical mind.

Most physical scientists believe that the world operates according to well-known physical laws and that most everything can be explained in terms of physics and chemistry. I am among them. We have strong faith in the scientific method, observing, testing multiple hypotheses, and throwing them out in order until we accept the surviving hypothesis (or few). Scientists are always studying the world, learning, and discovering. We accept that the process should involve high levels of self-critique and peer review. We should be glad to disprove our own hypotheses or have our hypotheses be disproven, as that invariably leads to formulation of better hypotheses and brings us closer to the truth.

Jasanoff (1996) and Bäckstrand (2003) describe civic science: participatory, democratic, and addressing often-controversial societal problems without simple right or wrong answers, and with meaning derived from both absolute knowledge and human context. Civic science stands in contrast to conventional academic science that seeks to prove or disprove hypotheses, creating "absolute" knowledge within the scientific community that may or may not be used by decision makers, and that almost never involves citizens. On controversial matters involving big business, civic science also stands in contrast to science which promotes corporate interests. Most scientists are trained for conventional academic science, and can easily enter the proprietary world of corporate science. Those who will join in civic science must expect greater democracy and relativism than in standard university training.

What does civic science have to do with natural hazards? After all, aren't natural hazards wholly apolitical? No, decisions must still be made, sometimes even controversial decisions, and the more transparent and democratic the scientific process, the more trust will be established. One excellent example of civic volcanology is the network of vigias around Tungurahua Volcano in Ecuador, where an early overestimation of hazard created distrust of volcanologists that had to eventually be reversed, and an important part of that reversal was inclusion of local residents as scientific observers and alerters (Stone et al. 2014).

Where decision makers and engineers do rely on scientists for information on hazards and risk, there comes a serious responsibility for those scientists to resolve normal differences of interpretation. Scientific teams must try to resolve scientific debates and then present a consensus view to decision makers. If some issues cannot yet be resolved, it is fine to present them as competing hypotheses and explain how we will try to test them [from the field of climate change, see advice by Socolow (2011)]. Scientific credibility will still be intact. But if several different scientists offer competing advice, decision makers must decide who to believe. Personalities and trust, as much or more than evidence, become deciding factors. If scientific debate still rages in public, officials will lose faith in all scientists.

Many citizens "learn" by trusting a charismatic public figure - be it a politician, a cleric, a media figure, or anyone else. Sometimes, a 
scientist with unusually good communication skills and a knack for simplifying and popularizing scientific concepts can be the charismatic figure, but there is a risk that such scientists will fall into the trap of dogmatism unless they listen carefully to all scientific views before making public pronouncements. Charisma should be paired with humility, as I have seen cases in which good scientists became overly confident of their own expertise and Nature has proven them wrong.

Other citizens learn by their own observations, and by oral traditions. Traditional knowledge includes non-scientific explanations of the natural world that may or may not have a basis in physics or chemistry. For example, traditional knowledge around some volcanoes that water wells dry up before eruptions has a good physical explanation. But other "knowledge" (belief) has no physical explanation and is, instead, based on religious faith. This group of citizens will be equally or more convinced by traditional explanations as by those from scientists. A good case in point involved the late Mbah Marijan, spiritual gatekeeper of Merapi, who was trusted by a group of followers to know from conversations with the spirits of Merapi whether their place would be in danger or not (Schlehe 2010; Donovan et al. 2012) and, more broadly, how that augured for future national events (Dove 2010). Once differences in jargon are overcome, social scientists can help physical scientists to understand that the latter's physical explanations may or may not trump traditional knowledge.

Sixth, we have different resources and tools at our disposal. Typically, scientists have moderate to good resources for literature review, gathering of new data, computing, and sharing results through scientific meetings and publications. We may also have extensive experience with other volcanic crises - something that is rare for those with whom we work.

Engineers have resources for design and implementation of structural measures-often much more, in monetary terms, than resources of scientists. This is a natural consequence of the cost of such structural measures, and in most cases is accepted as necessary. However, this discrepancy between funding for science and engineering intervention can become a sore subject for scientists if engineers are not utilizing the best available scientific information, and end up wasting large amounts of money on structures that scientists anticipate will not work. At Pinatubo, much money was spent on building woefully inadequate sediment control structures before engineering measures eventually grew large enough to handle the threat (Janda et al. 1996). At Merapi, in retrospect, sediment control structures actually caused pyroclastic flows to jump out of stream channels and thereby increased the death toll (Lube et al. 2011; Baxter et al. in press).

Civil defence officials, land managers, and politicians typically have the authority and resources to control public access to areas near a volcano, to support an evacuation if needed and, sometimes, to fund engineering intervention. In a few countries, civil defence agencies provide substantial funding to scientists and, in return, can expect projects that address their very practical concerns. The news media have, by the nature of their work, great communication resources. They have the ear and the eye of the public and, if they choose to do so, they can be wonderfully effective in translating scientific information into terms that others can use and facilitating two-way communication with scientists.

Citizens have only their own eyes and ears, but often have the advantage of living on the volcano and being able to spot changes that escape modern instruments. A case in point is that local farmers reported the start of the flank eruption of Eyjafjallajökull in 2010 to police and scientists, not vice versa (Bird and Gísladóttir 2012). A number of eruptions in remote areas like the Aleutians are reported first by airline pilots who are constantly scanning their horizons for any in-flight hazards. 


\section{TRUST Between Scientists and Non-scientists Is Critical for Successful Risk Mitigation}

Given the significant cultural differences between players in a volcanic crisis, there will inevitably be scepticism and a period of adjustment before each group is comfortable with the others. Perhaps the biggest challenge is to develop trust between the various players. More specifically, trust between scientists and those who use scientific information is essential if that information is to be accepted and used (Paton 2007; Haynes et al. 2008a, b; Donovan et al. 2014; Stone et al. 2014). Trying to understand and accept the cultural differences among the various groups, and involving users in the scientific process whenever feasible, are the best ways I know to develop this trust. If the scientific team with an official mandate for advice doesn't reach out to develop such trust, decision-makers may very well look elsewhere for advice, including to scientists perhaps less qualified but more communicative, or even to pseudoscientists who seem to speak with authority.

Here are three examples where trust was critical for volcanic risk mitigation.

\subsection{Mount St. Helens 1980}

Capsule timeline: March 20, 1980, earthquakes start. March 27, first phreatic eruption. More phreatic eruptions and strong bulging of North flank. Sunday, May 18, massive sector collapse and laterally directed blast. Most forest workers were off work on Sunday; most would-be tourists had been kept out of the area but there was access for some tourists along a myriad of small logging roads. A lateral blast far larger than expected led to 57 deaths.

Years of friendly interaction between geologists of the US Geological Survey (USGS) and officials of the US Forest Service (USFS) had already establish good trust and credibility even before the volcano became restless in 1980. An excellent long-range hazard assessment had already been published in 1978, albeit not promoted or read as widely as it might have been.

Trust had also been developed over nearly a decade of interaction between seismologists of the University of Washington (UW) and a few USGS seismologists who worked at the University, and that served as a good introduction between the UW seismologists and other USGS scientists who came quickly to Vancouver, Washington.

As the crisis evolved, USGS and UW scientists and USFS/State officials grew to understand and appreciate each other's roles. Most of these roles were never in doubt: scientists would try to anticipate what the volcano might do; USFS and State officials would decide how to manage the risk. Aside from a few early hiccups in which officials asked the USGS what they should do and the USGS declined as a matter of agency policy, these complementary roles were well understood and accepted.

The USFS quickly established an Emergency Coordination Center (ECC), where they provided desks and phones for all of the other key parties (State of Washington Emergency Services, County Sheriffs, representatives of hydroelectric and nuclear power utilities, major timber companies). The Forest Service also organized daily briefings for these representatives and for the press. The ECC was great for building trust, as it also afforded opportunities for 1:1 consultations with the scientists about specific places, e.g., a specific bridge, road intersection, etc., free from the glare of TV cameras. Even before the giant landslide and blast on May 18, 1980, trust between scientists and USFS was strong.

The public, the news media, and the timber companies clamoured for unrestricted access. Fortunately for most, the USFS resisted and declared a red zone off limits to all and a blue zone with only limited access. Unfortunately, the Governor of the State of Washington bowed to political pressure and kept areas under her jurisdiction officially open. The Washington State Patrol tried to block access anyway, but 
couldn't legally do so, and most fatalities in the eruption occurred on land under State control (Saarinen and Sell 1985).

After the landslide and blast, the shock of events practically glued everyone together. The USGS stationed two scientists at the ECCone as liaison between the scientific team and the risk managers, and the other to provide consistent information to the news media. I came to Mount St. Helens not long after the landslide and blast, as the liaison to risk managers, and worked side-by-side for several years with USFS and State personnel. Because we worked in the same office, shared the same coffee pot, and heard the same conversations, we developed a mutual understanding of each other's needs and competencies, even idiosyncracies. We learned to "read" each other, and to learn from each other.

As mentioned above, USGS policy strictly forbade scientists from suggesting to public officials how they should manage risk. Any recommendation regarding evacuations or other mitigation measures contains an implicit assessment of acceptable risk, including personal, economic, and political matters well beyond the expertise or mandate of scientists. In the US, the public is staunchly, vehemently protective about personal freedoms, including the right to make most decisions about their own personal safety. While private citizens might take recommendations or orders from land-managers and law-enforcement, they certainly would not wish for their freedom to be "managed" by scientists. Recommendations about evacuations and other mitigation are political matters, all agreed. Nevertheless, there were times when Forest Service or other risk managers struggled to understand the hazard, and to decide on their response. In those cases, because we trusted each other, we held "off-the-record" conversations in which scientists actually went beyond their official limits to guide risk managers. We did not suggest what officials should do, but used personal risk tolerance as bridge. The Forest Service staff would ask us, "Would you personally stay in this place, or would you let your own family stay in this place?" Those were questions we could answer without going beyond our brief, yet our answers gave them the information they needed to make their own decisions.

As another example, we struggled together to reach a shared understanding of the magnitude of remaining risk, using probabilities. The Forest Service, timber companies, and loggers pushed us to simplify the presentation and to make the bottom line something that they could easily understand. The result was a chart ("risk ladder") on which volcanic risk, once calculated, could be compared at a glance to familiar risks (Fig. 1). The chart includes occupational risks (soldier in war, helicopter pilot, logger, office worker, etc.), lifestyle risks (lung cancer from smoking), and accident risks (traffic risks, risks from floods, lightning strikes, etc.). Probabilities per se meant almost nothing; locating one's risk on this chart made it instantly simple to decide whether a risk was acceptable or not. None of the parties - the timber company, loggers' union, or Forest Service - was concerned about high uncertainties or about caveats in comparing voluntary and involuntary risk.

Although the post-May 18 period had far less threat and drama than that during and before May 18 , trust and personal friendship that developed in the course of working together has continued to serve all parties well right up to the present, including the 2004-2008 eruptive period.

\subsection{Pinatubo 1991}

Capsule timeline: July 16, 1990: M 7.8 strikeslip earthquake with epicenter $100 \mathrm{~km} \mathrm{NE}$ of Pinatubo. April 2, 1991, phreatic explosions along a fissure across north-northeast flank of Pinatubo. Fluctuating unrest until escalation in early June. Extrusion of lava dome June 7-12. Strong VEI 3 scale eruptions June 12-14. Climactic VEI 6 scale eruption and caldera formation on June 15. Most of those at risk from pyroclastic flows had been evacuated by June 14, just barely in time.

Because Pinatubo had no historic eruptions, officials of Central Luzon had no established relations or trust with Philippine scientists. There was, however, a well-established relationship and 


\begin{tabular}{|c|c|c|c|c|}
\hline $\begin{array}{l}\text { Annual } \\
\text { Risk }\end{array}$ & Age & Occupation & Disease & Accident \\
\hline \multicolumn{5}{|l|}{$10^{\circ}$} \\
\hline \multirow{3}{*}{$10^{2}$} & 90 & & & \\
\hline & & & & \\
\hline & 80 & Soldier in war & & \\
\hline \multirow[t]{3}{*}{$10^{-2}$} & 60 & & & \\
\hline & so & Helicopter pilots & Heart disease & \\
\hline & & Logging & Cancer & \\
\hline \multirow[t]{2}{*}{$10^{-3}$} & 20 & & AIDS, Sub-Sahara & \\
\hline & & $\begin{array}{l}\text { Mining } \\
\text { Agriculture }\end{array}$ & & $\begin{array}{l}\text { All accidents } \\
\text { Car accidents }\end{array}$ \\
\hline $10^{4}$ & & $\begin{array}{l}\text { Transport, construction } \\
\text { All workers (avg.) } \\
\text { Manufact'g, retail, gov't }\end{array}$ & AIDS, industrial'zd & \\
\hline 10 s & & & & Drowning \\
\hline$\ldots$ & & & & Hurricanes \\
\hline
\end{tabular}

Fig. 1 Risk ladder showing comparative annual risks to life, in the US, circa 2000. Simplified and updated from that originally used in Newhall (1982) to help loggers and timber company managers understand volcanic risk they faced in salvaging blown-down timber. Assuming good volcano monitoring, communications, and willingness to

trust between the National Disaster Coordinating Council (civil defence, NDCC) and the Philippine Institute of Volcanology and Seismology (PHIVOLCS). Starting from the top, this relationship and trust was brought down to the provincial and municipal levels. Initially, local scepticism was extremely high, so trust at the local level took a long time to develop, but a combination of many briefings and increasingly visible signs from the volcano itself eventually turned the tide and allowed evacuation of the riskiest areas before the eruption (Newhall and Punongbayan 1996; Punongbayan et al. 1996; Newhall and Solidum, this volume).

The slopes of Pinatubo were home to an indigenous people, the Pinatubo Aytas. Centuries of discrimination and distrust led most Aytas to shun interaction with lowland Filipinos. Few of the Aytas understood anything of modern science, and most believed that Mount Pinatubo was the home and domain of their god Apo Namalyari, so anything that happened at Pinatubo would have to be explained as an action of Apo Namalyari. A few of the responding PHIVOLCS scientists spoke Kapampangan or stop work during elevated volcanic unrest, the added annual risk to each logger's life was $\sim 0.0012 / \mathrm{y}$ ( \pm one order of magnitude), or approximately the same as a logger's normal occupational risk though with higher uncertainty

Ilocano, languages familiar to all of the Ayta, but none of the scientists spoke any of the Ayta dialects, nor were there any longstanding relationships. Fortunately, there were several trusted religious missions on Pinatubo- one of the Franciscan Sisters of Mary northwest of the summit, and two of evangelical Protestant missionaries north and south of the summit. The communication gap between scientists and indigenous Aytas was bridged by these trusted missionaries.

Longstanding trust between USGS and PHIVOLCS scientists also helped greatly in this crisis, and I suspect that it helped in the larger task of developing trust and credibility with local officials. Had we scientists ourselves not been completely unified, our task to dissolve official and public scepticism and promote preparedness could easily have foundered.

The matter of trust with commanders of the US military bases was particularly complicated. The Pinatubo crisis arose in the midst of a tense renegotiation to extend the lease for US bases in the Philippines, and there was little trust between officials of US military bases and those of the 
Philippine government. Initial warnings from Philippine scientists were dismissed, and US commanders only began to pay attention when USGS scientists were invited in by PHIVOLCS. Even then, scepticism remained high, as the US scientists had to be conscious of their first duty to the Philippine government and populace. Gradually, though, daily interactions and a growing body of worrisome facts about the volcano dissolved scepticism one officer at a time. The joint PHIVOLCS-USGS team received critical logistical support from the US military (especially, the US Air Force), and the US military in return received notices at the same time as Philippine civil defence officials, and had access to the scientific team for additional discussions.

Two seemingly minor incidents at our makeshift observatory on Clark Air Base greatly improved trust and understanding of our message. The first was the anniversary of the big eruption of Mount St. Helens, on May 18. After working day and night since early April, the team took a day off on May 18 to relax, and invited military officers over for a BBQ and beer. There, we could talk about our families, fun, and matters other than the volcano, and we noticed a palpable improvement in relations with the military officers. They saw, for the first time, that we scientists were human and not much different from themselves! We even had a sense of humour. Amazing (:)

The other incident was soon thereafter, when scientists started looking for a fall-back position on Clark Air Base, as far from the volcano as possible. The very fact that we were concerned for our own safety in the middle of Clark Air Base made the officers take notice. Suddenly, things we had discussed many times before, including the possibility of pyroclastic flows reaching Clark Air Base, took on new meaning. On June 10, shortly after evacuation of most personnel from Clark Air Base to Subic Naval Station, the scientific team moved to the fallback position at the far edge of Clark Air Base, and some of the remaining military officers moved with the scientists.

\subsection{Usu 2000}

Capsule timeline: March 27, strong earthquake swarm and pronounced ground fracturing begins. March 31, explosive eruptions begin and continue for $\sim 3$ weeks while a cryptodome is simultaneously being emplaced. The main hazards were ballistic fragments, formation of new craters, widespread ground fracturing, and hot lahars. Timely evacuations kept everyone safe.

Usu Volcano, in Hokkaido, Japan, has a history of explosive eruptions and cryptodome growth over many centuries, most recently in 1910, 194344, and 1977-1982. In those same crises, there was unusually good trust between scientists, police officials, and mayors. In the case of 1910, the police chief Mr. Iida had been a student of the leading volcano and earthquake scientist of the time, Prof. Omori at Univ. of Tokyo, so the contact and respect was already established. The crisis of 1943-44 came during WW II, and scientific response was led by another senior professor from Univ. of Tokyo, Prof. T. Minakami. The postmaster, Mr. S. Mimatsu, was an amateur scientist and worked closely with Prof. Minakami. (Mr. Mimatsu's son still maintains a volcano museum near Usu).

After the 1943-44 eruption, tourist development and population increased significantly. Risk at Usu arises because towns lie extraordinarily close to the volcano, just $2-3 \mathrm{~km}$ from the summit and even less from flank vents. For fear of scaring away tourists, there was strong resistance to discussion of volcanic hazards. However, Prof. Hiromu Okada had learned from study of previous crises that the key to risk mitigation had been trust and respect between early scientists and police officials. So, Prof. Okada took on the personal challenge of frequent interaction and trust-building with local officials, especially local mayors. He managed to change the conversation from "Don't mention volcanic hazards!" to "OK, if we listen to the scientists, educate the public, and back off briefly when needed, we can safely co-exist with these volcanic hazards!" Mayor Okamura of Abuta town 
was an early convert. Prof. Okada's personality is excellent for building trust and, in 2000, when another magma intrusion (cryptodome) was rising, people were safely evacuated ahead of phreatic explosions that damaged many buildings. It was an outstandingly successful case of volcanic risk mitigation in Japan.

\section{Concluding Tips}

When a volcano awakens, volcanologists and other scientists will need to work with civil defence leaders, politicians, business leaders, engineers, news media and, sometimes, citizens. Most scientists are not trained for such interaction, and the interaction can be challenging. There will be an initial period in which each group is simply trying to get to know the other, and to assess each other's motives, technical competence, and judgment. Scientists will be under a spotlight, since scientific information will become a major factor in mitigation decisions.

Wide cultural differences exist between volcanologists and those who use volcanological information, and these differences must be understood and respected if there is to be trust between both groups. How can this understanding be achieved? The following tips are especially for volcanologists, but may apply as well to other players.

- Work in close proximity as much as you can, and try to understand each other's culture and needs. Volunteer to work side-by-side in space organized by and for those needing volcano information.

- Expect scepticism, and do not take it personally. Things that may signal obvious danger to a scientist, e.g., a town built on a pyroclastic flow deposit or unusual squiggles on a seismogram, may not be at all obvious to others, and the onus is on those who see danger to convince others that it is real. Try to relate it to what the audience knows and cares about.

- Involve those who need volcano information in the gathering and dissemination of that information. Users become partners in the scientific process.

- Be professional, patient, and show that you want to help those at risk and those who must make mitigation decisions. Without pre-empting the decision maker's responsibility, share insights into your own personal risk tolerance.

- Remember, we scientists may seem to be from another planet. Bring humility and a sense of humour to the table. Share personal aspirations and worries, notes about families, and other common interests, and food and drink as well. Invite your counterparts out for a beer, or a picnic, or birthday party, or make any other simple, personal gestures to move your interaction from strictly formal to space in which you see the more human sides of each other.

- Personal trust that grows out of such interaction is a critical prerequisite before officials will make the necessary, hard decisions for mitigation.

- Once trust has been built, be careful to maintain it. Obviously, correct forecasts will build and maintain trust, but so, too, can humility and honest statements of uncertainty when we don't know what the volcano will do next.

In every interaction, professionalism, cross-cultural sensitivity, and personal touches make a powerful combination. Good luck!

Acknowledgements Thanks to Kevin Krajick, Earth Institute of Columbia University, for helpful pre-review comments, and to anonymous reviewers who pointed the author to relevant social science literature, the importance of distinguishing opinions from evidence, and necessary clarifications.

\section{References}

Bäckstrand K (2003) Civic science for sustainability: Reframing the role of experts, policy-makers, and citizens in environmental governance. Global Environ Politics 3-4:24-41

Baxter P, Jenkins S, Rosadi S, Komorowski J-C, Dunn K, Purser D, Voight B, Shelley I (in press) Human 
survival in volcanic eruptions: thermal injuries in pyroclastic surges, their causes, prognosis and emergency management. Burns Accessed on 21 Feb 2017

Bird DK, Gísladóttir G (2012) Residents' attitudes and behaviour before and after the 2010 Eyjafjallajökull eruptions - a case study from southern Iceland. Bull Volc 74:1263-1279

Bultitude K (2011) The why and how of science communication. In: Rosulek P (ed) Science Communication. European Commission, Pilsen, 18 p. https://www. ucl.ac.uk/sts/staff/bultitude/KB_TB/Karen_Bultitude_--

Science_Communication_Why_and_How.pdf. Accessed 10 Nov 2014

Dean C (2009) Am I making myself clear? A scientist's guide to talking to the public. Harvard University Press

Donovan K, Suryanto A, Utami P (2012) Mapping cultural vulnerability in volcanic regions: the practical application of social volcanology at Mt. Merapi, Indonesia. Env Hazards 11:303-323

Donovan A, Eiser JR, Sparks RSJ (2014) Scientists' views about lay perceptions of volcanic hazard and risk. J Appl Volcanol 3:15, $14 \mathrm{p}$

Dove MR (2010) The panoptic gaze in a non-western setting: self-surveillance on Merapi volcano, Central Java. Religion 40:121-127

Doyle EEH, Potter SH (2015) Methodology for the development of a probability translation table for GeoNet. GNS Science Report 2015/67, 18 p

Fischhoff B (2011) Applying the science of communication to the communication of science. Clim Change 108(4):701-705. doi:10.1007/s10584-011-0183-9

Graveline D (2013) 7 ineffective habits of scientists who communicate with public audiences. http://www. dontgetcaught.com, 19 Feb 2013. Accessed 10 Nov 2014

Harris F, Lyon F (2013) Transdisciplinary environmental research: building trust across professional cultures. Environ Sci Policy 31:109-119. doi:10.1016/j.envsci. 2013.02.006

Hayes R, Grossman D (2006) A scientist's guide to talking with the media: practical advice from the Union of Concerned Scientists. Rutgers University Press. Excerpts at http://www.ucsusa.org/sites/default/ files/legacy/assets/documents/global_warming/UCS_ Desk_Reference_Scientists_Guide.pdf

Haynes K, Barclay J, Pidgeon N (2007) Volcanic hazard communication using maps: an evaluation of their effectiveness. Bull Volc 70:123-138

Haynes K, Barclay J, Pidgeon N (2008a) The issue of trust and its influence on risk communication during a volcanic crisis. Bull Volc 70(5):605-621

Haynes K, Barclay J, Pidgeon N (2008b) Whose reality counts? Factors affecting the perception of volcanic risk. J Volcanol Geoth Res 172:259-272

Janda RJ, Daag AS, Delos Reyes PJ, Newhall CG, Pierson TC, Punongbayan RS, Rodolfo KS, Umbal JV (1996) Assessment and response to lahar hazard at Mount Pinatubo. In: Newhall CG, Punongbayan RS (eds) Fire and mud, eruptions and lahars of Mount
Pinatubo, Philippines. Quezon City, PHIVOLCS and Seattle, University of Washington Press, pp 107-139

Jasanoff S (1996) Beyond epistemology: relativism and engagement in the politics of science. Soc Stud Sci 26:393-418

Kennedy D, Overholser G (eds) (2010) Science and the media. American Academy of Arts and Sciences, Cambridge, MA, 95 p. www.amacad.org/pdfs/ sciencemedia.pdf

Lube G, Cronin SJ, Thouret J-C, Surono (2011) Kinematic characteristics of pyroclastic density currents at Merapi and controls on their avulsion from natural and engineered channels. Geol Soc Am Bull 123:11271140. doi:10.1130/B30244.1

Manning P (2006) Communicating effectively with politicians. Physics in Canada. June-July 2006, pp 163-168. http://www.interactions.org/pdf/SLAC_ pavan_manning.pdf

Mastrandrea MD, Field CB, Stocker TF, Edenhofer O, Ebi KL, Frame DJ, Held H, Kriegler E, Mach KJ, Matschoss PR, Plattner G-K, Yohe GW, Zwiers FW (2010) Guidance note for lead authors of the IPCC fifth assessment report on consistent treatment of uncertainties. Intergovernmental panel on climate change (IPCC). Available at: http://www.ipcc-wg2.gov/mee tings/CGCs/Uncertainties-GN_IPCCbrochure_lo.pdf

Morgan MG (1998) Uncertainty analysis in risk assessment. Human Ecol Risk Assess 4(1):25-39

Morgan MG, Henrion M (1990) Uncertainty: a guide to dealing with uncertainty in quantitative risk and policy analysis. Cambridge University Press, 348 p

Moss RH (2011) Reducing doubt about uncertainty: guidance for IPCC's third assessment. Clim Change 108:641-658. doi:10.1007/s10584-011-0182-x

Newhall CG (1982) A method for estimating intermediate- and long-term risks from volcanic activity, with an example from Mount St. Helens, Washington. US Geological Survey Open-File Report 82-396, $59 \mathrm{p}$

Newhall CG, Punongbayan RS (1996) The narrow margin of successful volcanic-risk mitigation. In: Scarpa R, Tilling RI (eds) Monitoring and mitigation of volcanic hazards. Springer, Berlin, pp 807-838

Newhall CG, Solidum RU (this volume) Volcanic hazard communication at Pinatubo from 1991 to present. In: Fearnley CJ, McGuire B, Jolly G, Bird D, Haynes K (eds) Observing the volcano world: volcano crisis communication. Springer

Olson R (2009) Don't be such a scientist. Island Press, Washington $206 \mathrm{p}$

Paton D (2007) Preparing for natural hazards: the role of community trust. Disaster Prev Manag 16(3):370-379

Pidgeon N, Fischhoff B (2011) The role of social and decision sciences in communicating uncertain climate risks. Nat Clim Change 1:35-41

Punongbayan RS, Bautista MLP, Harlow DH, Newhall CG, Hoblitt RP (1996) Pre-eruption hazard assessments and warnings. In: Newhall CG, Punongbayan RS (eds) Fire and mud: eruptions and lahars of Mount Pinatubo, Quezon City, Philippine Institute of 
Volcanology and Seismology, and Seattle, University of Washington Press, Philippines, pp 67-85

Renn O, Levine D (1991) Credibility and trust in risk communication (Chapter 9). In: Kasperson RE, Stallen PJM (eds) Communicating Risks to the Public. Kluwer Academic Public, Netherlands, pp 175-218

Saarinen TF, Sell JL (1985) Warning and response to the Mount St. Helens eruption. Albany, State University of New York Press, $240 \mathrm{p}$

Schlehe J (2010) Anthropology of religion: disasters and the representations of tradition and modernity. Religion 40:112-120

Open Access This chapter is licensed under the terms of the Creative Commons Attribution 4.0 International License (http://creativecommons.org/licenses/by/4.0/), which permits use, sharing, adaptation, distribution and reproduction in any medium or format, as long as you give appropriate credit to the original author(s) and the source, provide a link to the Creative Commons license and indicate if changes were made.
Socolow RH (2011) High-consequence outcomes and internal disagreements: tell us more please. Clim Change 108(4):775-790. doi:10.1007/s10584-0110183-9

Stone J, Barclay J, Simmons P, Cole PD, Loughlin SC, Ramón P, Mothes P (2014) Risk reduction through community-based monitoring: the vigias of Tungurahua, Ecuador. J Appl Volcanol 3:14 p. doi:10.1186/ s13617-014-0011-9

The Earth Institute, Columbia University (2014) Communicating science. http://www.earth.columbia.edu/ articles/view/2636. Accessed 10 Nov 2014
The images or other third party material in this chapter are included in the chapter's Creative Commons license, unless indicated otherwise in a credit line to the material. If material is not included in the chapter's Creative Commons license and your intended use is not permitted by statutory regulation or exceeds the permitted use, you will need to obtain permission directly from the copyright holder. 